\title{
Using a 3D Technology in the Network Distance Teaching of "Sports Training"
}

\author{
http://dx.doi.org/10.3991/ijet.v11i05.5693 \\ Yongsheng Qi, Youguo Shi \\ Bengbu Medical College, Bengbu Anhui, China
}

\begin{abstract}
As a new modern educational technology, the real time recording and playing has great significance in promoting distance learning, independent study and teaching quality. This research designed and developed a distance learning platform for students majoring in physical education based on 3D technology and real-time recording and playing technology. Through 3D technology, this teaching platform includes functions such as: overall module of $3 \mathrm{D}$ real time recording and playing, access to information, generation of 3D simulation video, video release and download module. Experimental results showed that teaching physical education curriculum with this platform can greatly improve learning efficiency and academic achievement; by innovating educational technologies of real time recording and playing system, so as to better promote the construction of distance education at the University.
\end{abstract}

Index Terms-real-time recording and playing, distance teaching, 3D technologies

\section{INTRODUCTION}

\section{A. Background}

Distance learning refers to a teaching approach that uses internet and other media for teaching [1]. Its teaching methods are different from traditional education approaches, and its dependence on the network technology is much greater than traditional education. Distance education must be combined with network technology, its teaching activities and model design should also consider the characteristics of internet technology. The most mainstream technologies nowadays include: streaming media technology [2], computer-aided instruction [3], virtual reality technologies and Web page technologies [4]. Designing a teaching model that is inline with benign development of distance education under the guidance of modern teaching concept, study theory and instructional design theory is the key to ensure teaching quality of distance education. With the development of the internet technology and increasing support and promotion of distance education by the government, application of distance education is gradually extending, its corresponding teaching methods are implemented in various fields such as in military simulation training, remote medical teaching, distance computer education and many other areas [5].

With the technological progress and increasing pace of life, many students hope that they can receive quality education anywhere, anytime. Real time recording and playing system happens to have merits of not being restricted by time or location. This modern educational technology has gained attentions from many educational researchers, and has been widely used. Real time recording and playing system can record teachers' or the speak- er's image (Video), sound (Audio) and lecture notes (VGA) into a standard network format with hardware device that can play instantly via live network and server. Audience can watch the live audio, video and graphic content via IE and Media Player. At the end of the speech, content will be saved or stored immediately on disc or the server, providing sourcing broadcast (VOD) service [6]. Setton E and Yoo $\mathrm{T}$ explored the potential synergies of exchanging information between different layers to support real-time video streaming. In this new approach, information is exchanged between different layers of the protocol stack, and end-to-end performance is optimized by adapting to this information at each protocol layer, and satisfactory application effects are achieved [7]. Lu F and Pingping S. combined real time recording and playing system with the quality course teaching at the University. Using real-time recording and playing technology can help students learn without time or location restrictions, this method of distance education in China are accepted by many students and teachers [8]. Mehta N B innovated real time recording and playing in medical education and its teaching application method according to the medical education system. These innovations include collaboration among medical schools to develop massive open online courses for didactic content; faculty working in small groups to leverage this online content in a "flipped-classroom" model; and digital badges for credentialing entrustable professional activities over the continuum of learning, by validation, new teaching methods can achieve certain teaching effects [9]. Lei Junxia and others used real time recording and playing system in the functional experiment teaching, during which it can play HD-quality video of experiment, thus guiding students to operate. In accordance with the current status of the virtual reality technology, application of real time recording and playing system for teaching is more suitable for previewing and students ' self-regulated learning for exams [10]. However, China, as a developing country, there is still a certain distance in the level of educational technology compared with Europe and the United States. These above-said real time recording and playing system is only used in theory teaching, and there are few official reports on its application on practical training courses currently. There are two approaches in our current training courses, one is that teachers would demonstrate with students gathering around to watch, but because there are so many students, the students seating far would not be able to see clearly, and it also increase the risks when they all seat together; the other approach is that students seat in their own seats and watch teachers' demonstrations, but because the back seats are far, the students there would also unable to see clearly, furthermore, these traditional ways can not achieve storage of training course, or online study, review, or regulation [11]. 


\section{B. Advantages of this research}

Three-dimensional modeling is one of the matured technologies in application, and current three-dimensional software including 3DMAX, MAYA, SOFTIMAGE, and so on [12]. Use them to design the three-dimensional modeling in sports training can produce three-dimensional human figure, equipment and scene, by switching among elements and scenes, it can simulate various sports techniques so that good teaching demonstration effects can be achieved with its lifelike motion.

First, this study applied 3D technology in sports training courses, it was based on network distance teaching. And effects of 3D remote education platform on the course of sports training was verified by application.

Second, this research combines 3D technology and realtime recording \& playing system. It has advantages such as HD and autonomy. recorded 3D video can be uploaded to database and website with streaming media technology allowing students to $\log$ in and download for independent study; and this improves real time recording \& playing system allowed students watch the teaching video in their seats clearly and intuitively, which results in significant enhancement of learning effect.

\section{Design And Production Of ReAl-Time} RECORding \& Playing Distance TEACHING Platform

\section{A. Real time recording \& playing remote teaching platform technologies and frameworks}

This system uses Ext-JS technology for the design of system front end and ASP. Net technologies for transforming Web application model. System is designed with object-oriented technology; client version is IE6.0 and above browsers, Visual Studio 2008 (C\#) and EXT-JS as a front-end developer; JavaScript as the main programming language, database is MSSQL2005. Its users and scope of the system are fully taken into account in the design and development process, efforts are made to make it highly flexible, secure with good user experience.

3D simulation video in this paper uses streaming media technology to upload to databases and Web sites, for students to browse and download. Streaming media technology is to compress continuous sound and image information and upload onto a network server for the viewer to watch while downloading; it is an instant watching technology. Our PE teaching course has higher requirement for continuity and consistency of action, which can fully achieve the stability of animation. Meanwhile, it also has great compression ratio, which allows it use less bandwidth and storage space. Therefore, even major sports video courseware can be compressed to a very small one, enabling student to take advantage of the limited network resources to watch and learn in real time.

\section{B. Design of key modules on remote teaching platform}

The platform contains a total of four main modules, mainly responsible for four functions such as the information collection, 3D simulation video generation, video display and video downloading. (figure 1)

(1) Overall module based on 3D real time recording and playing

graphics workstation, 3D terminals, multimedia teaching display terminal and Server on campus network. Among which, 3D HD camera connects HD graphics workstation through wire, HD graphics workstation connects 3D play terminal through wire, 3D play terminal connects teaching display terminal through wireless signal, quantity of teaching display terminals are the same with that of learning students, teaching display terminals are placed in seats, so the students can watch teaching in their seats clearly and intuitively, which can enhance class effect significantly. Finally, campus network server connects graphic workstation via a wireless signal. So that the students can access the teaching and review via campus network, they can also download video after logging in, it is easy to use and can achieve better learning effect. (see figure 2)

(2) 3D data acquisition modules for real time recording and playing system

Physical movements in sports training are multi-axis motions of the human body, made up of multiple parts of the body as a whole, connected by joints between the parts. Therefore, there are two factors for expressing body postures in information acquisitions [11]: one is taking the whole human body as a single target, its gesture includes the body's position and direction in the three dimensional coordinate system; the other is the angle of body joints of the each part. This paper use auxiliary software tool for animation design: 3DMax for simulation of human motion in remote teaching platform.

The acquisition module uses 3D motion capture technology to capture the shape feature of moving targets. Three-dimensional motion capture technology is to obtain more accurate three dimensional statistics for movement of the human body through various types of sensor technologies, and it only requires model to perform in the experimental scene to get the key parameter of body movement. Method of Gaussian process dynamic model is used to model a human motion in a video image in the remote teaching platform. The key positions include palm, elbow joints, knees and other parts; signal collector is installed at these parts, through locating teachers to achieve dynamic capture, and store it in the system database. (see figure 3)

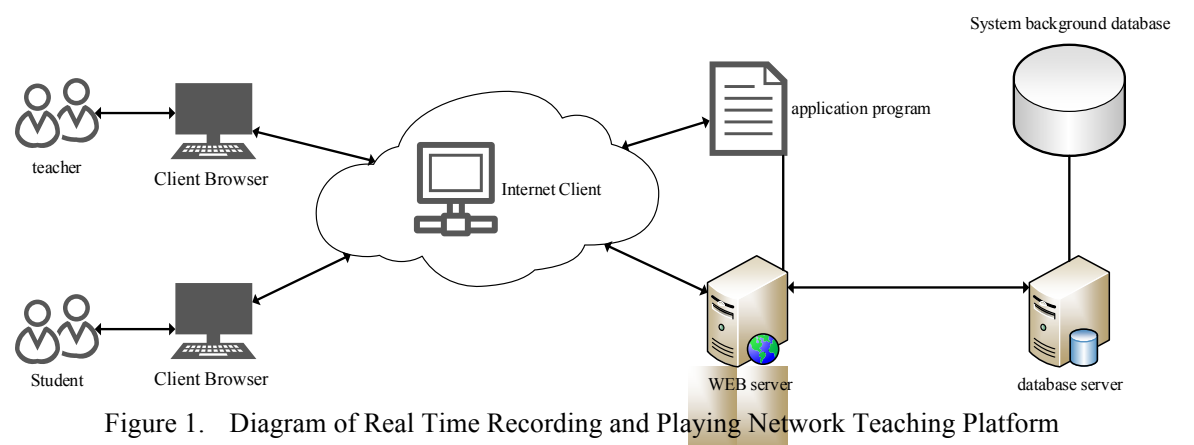




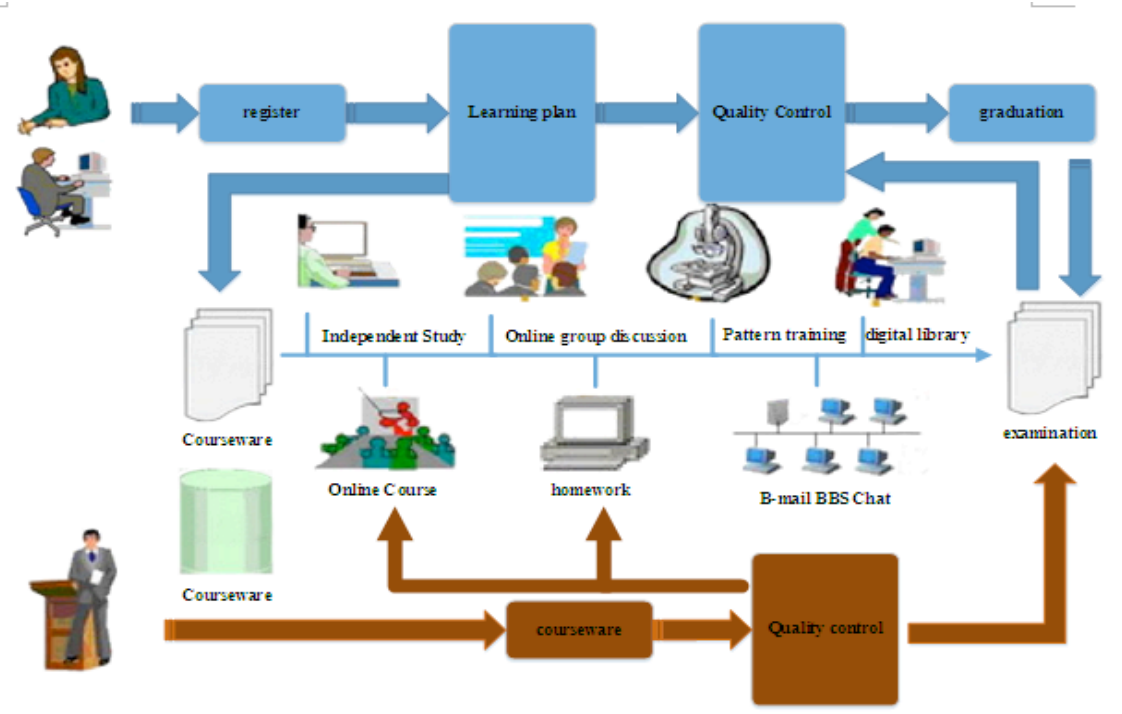

Figure 2. The overall module structure diagram of real-time recording

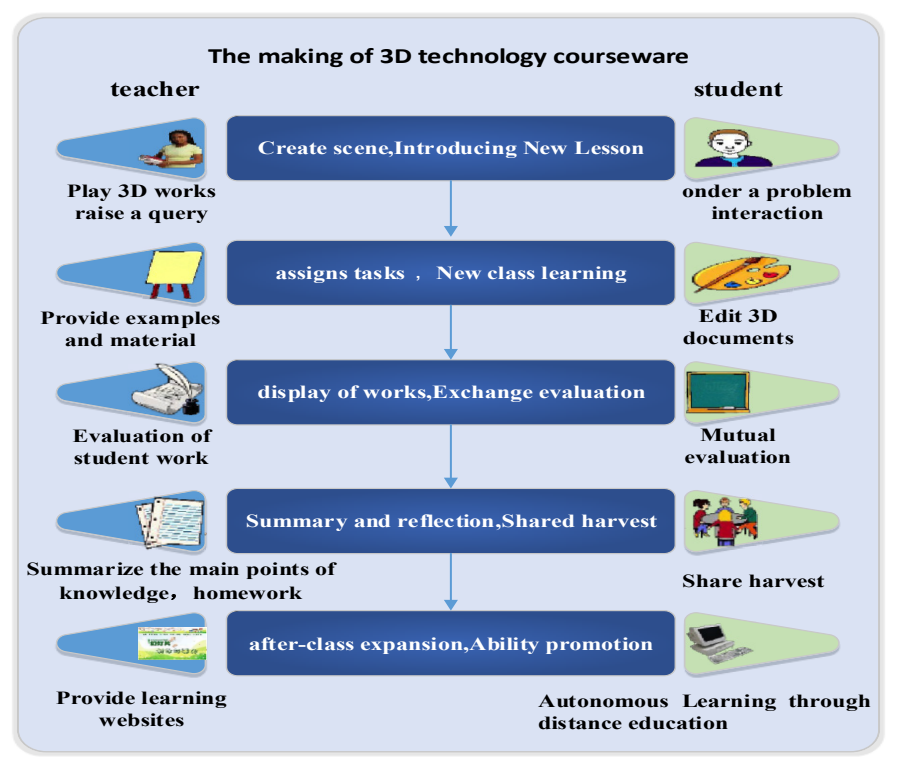

Figure 3. Real time recording and broadcasting network courseware structure

(3) Analog video generation module of real time recording and playing system

3D analog video generation module is completed by collection of multi-angle eigenvalve. Because sensor devices are installed at the key parts of sports performer's body, allowing software to automatically collects coordinate information at multiple angles and generates a series of analog video with teaching staff's sports actions.

The system will break down the motion analog video by key-frame to allow students study decomposed sports action. Commonly used key key-frames option is "single action demonstration" method, while in distance teaching system, graph node choose "continuous action" as the choice point for decomposition. The default design of the software are: whenever jumping, turning, balancing, or reversal appears in "continuous action", the software would design a key-frame corresponding to the action. System will save after completing key frame selection, followed by the action connection between the key frames to generate a complete analog video.
(4) Video download module of real time recording and playing system

Analog video download module is used to provide offline study functionality, mainly applies to those students who are unable to attend classes, or require multiple movement exercise. The module can generates offline video file package, save progress file, automatically detects off-line video and download, it also can keep track of students ' study status. It consists of the following steps: offline analog video detection (it detects whether or not the user has already downloaded the related videos); automatic download of offline simulation videos (after detection is complete, it will automatically download and save to the specified location via FTP), generate XML file based on the learning process, encrypt and store the file in the back-end database.

\section{Presentation of teaching platform of real-time recording \& playing (figure 4 and figure 5)}




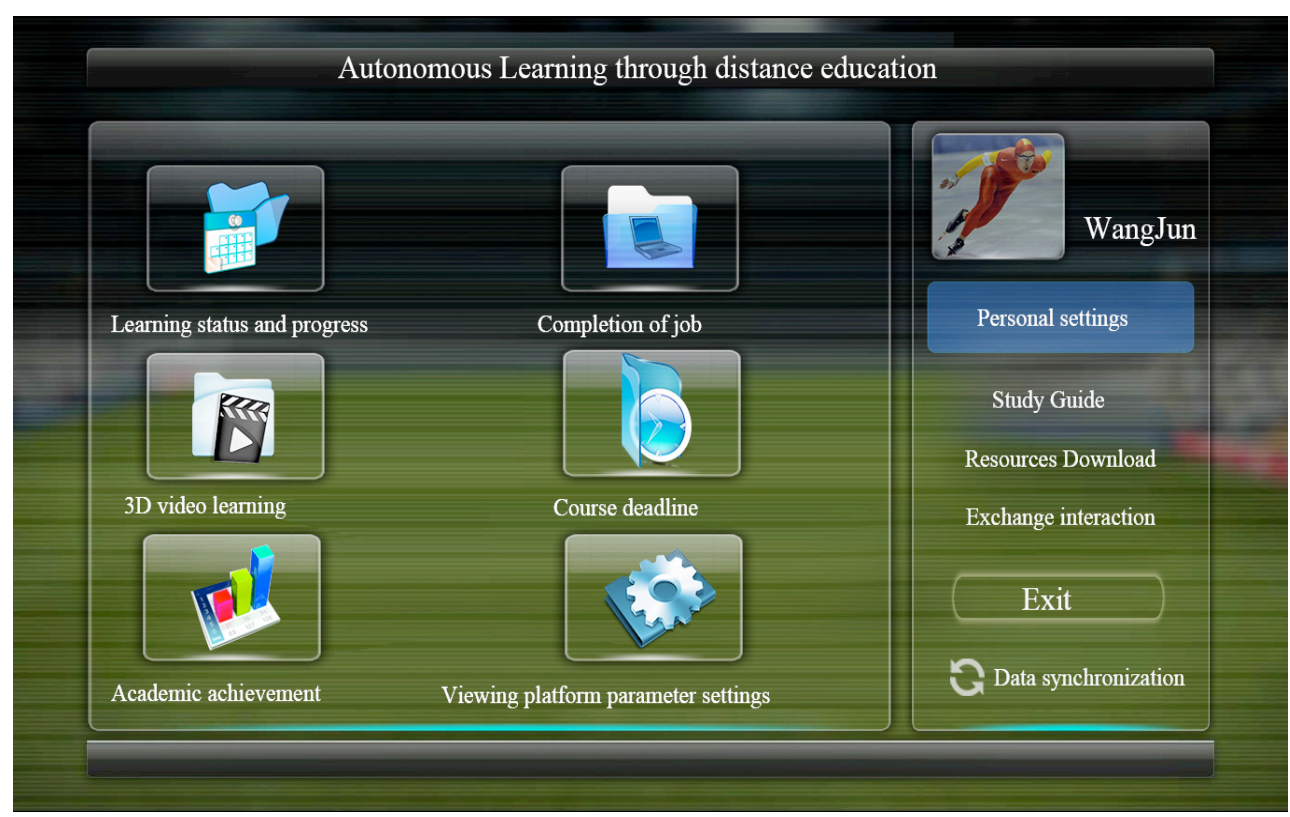

Figure 4. Real time recording teaching platform

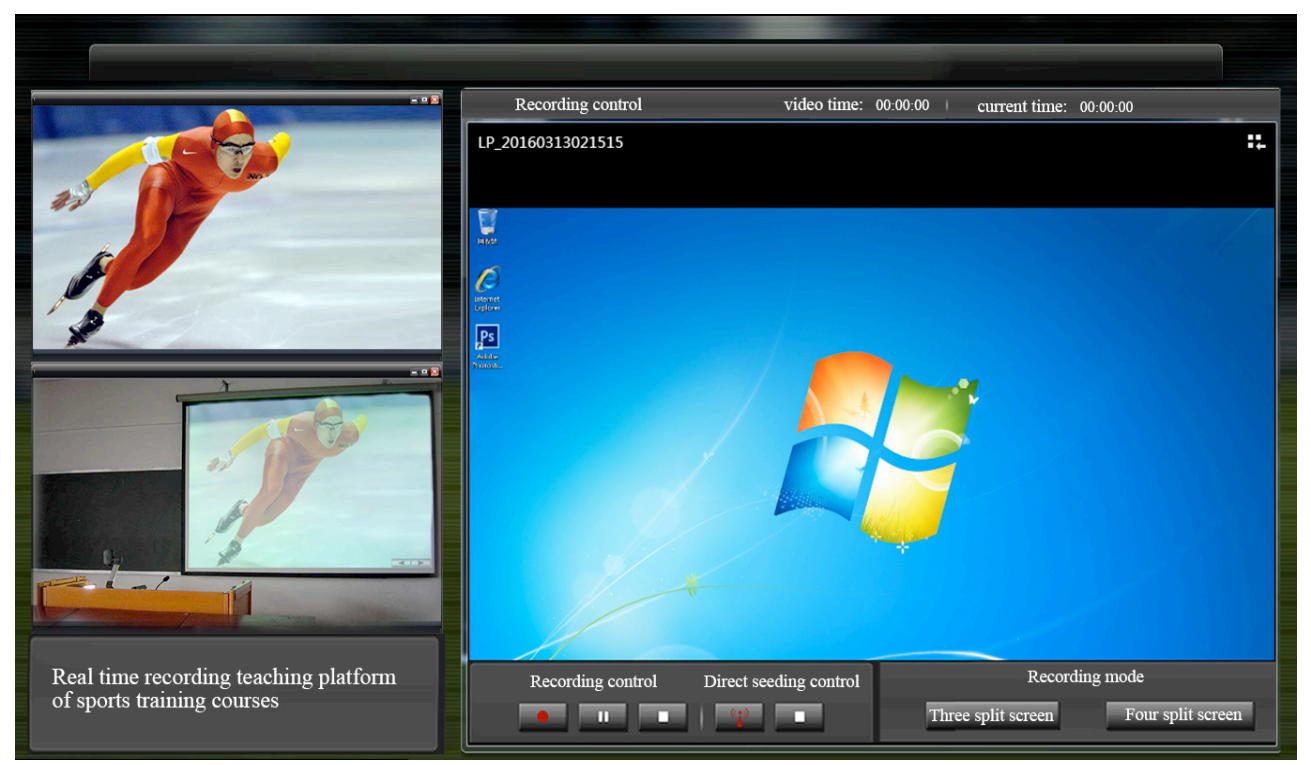

Figure 5. The teaching content of sports broadcasting real-time display

\section{APPLICATION OF REAL TIME RECORDing \& PLAYING SYSTEM IN ATHLETIC TRAINING}

\section{A. Experimental subjects}

Randomly select school students majoring in physical education as experimental subjects, the quantity of experimental students is 120 people (including 60 males and 60 females). Select 60 students from class $1-4$ as the experimental group, 60 students from class 5-8 as the control group. Students in the experimental group would study athletic training of PE on the distance teaching platform based on 3D technology and real time recording and playing technologies. Students in control group would study in traditional teaching methods. Course content and term and time arrangements for the two groups of students are the same, both are for one semester, with 56 study hours.

\section{B. Evaluation methods of learning outcome}

The experiment comprehensively evaluates effects of distance teaching platform based on real time recording and playing system on the study of athletic training from multiple aspects. First, scores at exam of each chapter and integrated scores at the final exams; second, proficiency of sports action after watching analog video on teaching platform; third, time spent on learning sports action of the same chapter and learning efficiency; fourth, students ' ability to appreciate the sports action; fifth, comprehensive performance in the final action evaluation.

\section{Experimental results}

After completing the course in one semester, evaluation of all students with the above evaluation criteria were conducted, the overall experimental results are shown in Table 1. 
TABLE I.

NETWORK Distance EdUCATION RESUltS OF EXPERIMENTAL GROUP (N)

\begin{tabular}{|c|c|c|c|c|}
\hline Experimental effects & Excellent & Good & Pass & Fail \\
\hline Scores from exams and comprehensive grades from the final exam & 34 & 21 & 5 & 0 \\
\hline Proficiency in sports action after completing certain phase & 41 & 11 & 3 & 5 \\
\hline Time spent on learning movements from the same chapter and learning efficiency & 39 & 7 & 8 & 6 \\
\hline Comprehensive appreciation ability for sports & 23 & 17 & 17 & 3 \\
\hline Overall performance in final movements performance & 31 & 15 & 11 & 3 \\
\hline
\end{tabular}

TABLE II.

TEACHING RESUlt OF CONTROL GROUP (N)

\begin{tabular}{|c|c|c|c|c|}
\hline Experimental effects & Excellent & Good & Pass & Fail \\
\hline Scores from exams and comprehensive grades from the final exam & 14 & 16 & 15 & 15 \\
\hline Proficiency in sports action after completing certain phase & 11 & 19 & 19 & 11 \\
\hline Time spent on learning movements from the same chapter and learning efficiency & 7 & 21 & 22 & 10 \\
\hline Comprehensive appreciation ability for sports & 17 & 22 & 17 & 4 \\
\hline Overall performance in final movements performance & 13 & 19 & 23 & 5 \\
\hline
\end{tabular}

By the analysis of the data in table 1 and table 2, we can see that: Although improvement of ability to appreciate of students in the experimental group is not significant, however, the proficiency level of sports action in experimental group is significantly higher than that of the control group (41 students in the experimental group are in excellent level, only 11 in control group). The system has certain advantages compared to traditional physical education. In addition, there are significant improvements in scores in exams and final exams, (34 students in the experimental group are in excellent level, only 14 students in control group are in excellent level; no students in experimental group fail in the final examination, while 15 students in the control group did not pass).

\section{CONCLUSIONS}

By applying real time recording and playing system in teaching experiment, we can see that this improved system yields good teaching results in actual training class. Mainly because: first, network distance teaching platform allows students arrange their study time with little restraints, there is sufficient time and no geological restrictions for them, they can study upon schedule or in advance. These conditions offer easy access to required knowledge for the students in experimental group, and they get hold of these knowledge better than students in control group; second, the system introduces $3 \mathrm{D}$ video simulation to actual training class teaching, this simulation technology has powerful modeling, animation display and data output function, these lifelike action demonstrations deepen their understanding of the body movements and strengthen their affection to sports while learning theoretical knowledge; in the meantime, improved real time recording and playing system allows students watching teaching process in their seats. It is clear and intuitive and can enhance efficiency significantly. It is able to demonstrate technical actions in details and various angles and directions, providing students rich theoretical and sports knowledge. It is the solution for inadequate and limited angle, direction, and frequency of demonstrations in traditional teaching. It liberates students from time limits of study and is conducive for students to evolve from perception study to cognitive study. It is free from weaknesses such as boring or monotonous; it can stimulate students ' learning initia- tive. Therefore, it is able to further enhance the students ' learning efficiency, improve teaching quality.

In short, real-time recording and playing system in combination with 3D technology can solve problems encountered in the practical teaching; it is also a modern teaching technology that is conducive to the development of modern physical education in universities.

\section{REFERENCES}

[1] Slater R., Pearson V. K., Warren J. P., Forbes T., "Institutional change for improving accessibility in the design and delivery of distance learning-the role of faculty accessibility specialists at The Open University," Open Learning: The Journal of Open, Distance and e-Learning, vol. 30, no. 1, pp. 6-20, March 2015.

[2] Chen W., Shih C.C., "Architecture of portable electronic medical records system integrated with streaming media," Journal of medical systems, vol. 36, no. 1, pp. 25-31, February 2012. http://dx.doi.org/10.1007/s10916-010-9442-y

[3] Yaghoobi M., Razmjoo S.A., "The potentiality of computerassisted instruction towards ameliorating Iranian EFL learners' reading level," Computers in Human Behavior, vol. 59, pp. 108114, June 2016. http://dx.doi.org/10.1016/j.chb.2016.01.033

[4] Craig C., "Understanding perception and action in sport: how can virtual reality technology help?" Sports Technology, vol. 6, no. 4, pp. 161-169, February 2014.

[5] Arinto P.B., "A framework for developing competencies in open and distance e-learning," The International Review of Research in Open and Distributed Learning, vol. 14, no. 1, pp. 167-185, March 2013.

[6] Demaerschalk B.M., Vegunta S., Vargas B.B., Wu Q., Channer D.D., Hentz J.G., "Reliability of real-time video smartphone for assessing National Institutes of Health Stroke Scale scores in acute stroke patients," Stroke, vol. 43, no. 12, pp. 3271-3277, December 2012. http://dx.doi.org/10.1161/STROKEAHA.112.669150

[7] Setton E., Yoo T., Zhu X., Goldsmith A., Girod B., "Cross-layer design of ad hoc networks for real-time video streaming. Wireless Communications," IEEE, vol. 12, no. 4, pp. 59-65, August 2005.

[8] Feng L., Song P.P., "Research on the Combination of University Video Open Courses and Excellent Courses," Journal of Hebei Radio \& TV University, vol. 19, no. 3, pp. 38-41, June 2014.

[9] Mehta N.B., Hull A.L., Young J.B., Stoller J.K., "Just imagine: new paradigms for medical education," Academic Medicine, vol. 88 , no. 10, pp. 1418-1423, October 2013. http://dx.doi.org/10.1097/ACM.0b013e3182a36a07

[10] Lei J.X., Lin W.J., Wu Y.P., Pan J.X., Tan H.M., "Study on Application of Real Time Recording and Playing System and Virtual Reality Technology in Functional Experiment Teaching," 
Journal of Chinese Medical Education Exploration, vol. 14, no. 3, pp. 283-285, March 2015.

[11] Wang J., Yang Z.G., Li Q.L., "Reform Exploration of Teaching Practice of Chemical Engineering Principle," Chemical Industry Times, vol. 28, no. 9, pp. 57-58, September 2014.

[12] Tanagho Y.S., Andriole G.L., Paradis A.G., Madison K.M., Sandhu G.S., Varela J.E., et al., "2D versus 3D visualization: impact on laparoscopic proficiency using the fundamentals of laparoscopic surgery skill set," Journal of Laparoendoscopic \& Advanced Surgical Techniques, vol. 22, no. 9, pp. 865-870, November 2012. http://dx.doi.org/10.1089/lap.2012.0220

\section{AUTHORS}

Yongsheng QI is a Lecturer of BengBu Medical College, Bengbu 233030, Anhui, China. His research interests include sports training and distance education. (qiyongshengA58@163.com)

Youguo SHI (Corresponding author) is a Lecturer of Department of Physical Education and Art, BengBu Medical College, Bengbu 233030, Anhui, China. His research interests include Sports Economics and Multimedia courseware. (shiyouguo1234@yeah.net)

Submitted 29 March 2016. Published as resubmitted by the authors 10 May 2016. 